\title{
Utilization of Antenatal Care services in Maternity Hospitals in Alexandria
}

\author{
Jilan A. Ibrahim Al-Battawi*
}

Abstract: Care during pregnancy is a major issue of women's health. The objective of such care is the birth of a healthy baby without any complications to mothers. However, adequate antenatal care can have serious impact on the current and future health of the mother and her off springs. This study aimed at assessing pregnant women utilization of antenatal care facility in maternity hospitals in Alexandria. This study was carried out in four maternity hospitals in Alexandria. The hospitals represent the different agencies involved in the provision of antenatal care. Ministry of health (Alexandria Governorate Hospital), University (El-Shateby Maternity Hospital), Medial Care Organization (Dar Elwelada Hospital), Health Insurance Organization (Gamal Abd El-Naser Hospital). A simple random sample consisting of 200 women were selected, 50 pregnant women from each hospital. The result of the present study revealed that in spite of improvement in antenatal care services, pregnant women utilization of antenatal care facility was still low. Poor quality of care was the most commonly reported reason $(49 \%)$, followed by the cost of service (39.5\%) and long waiting time (11.5\%).

\section{INTRODUCTION}

Every year more than 200 million women become pregnant. Most of these pregnancies end with the birth of a live baby to a healthy mother, while for others, childbirth is not the joyous event it should be, but it is a time of pain, fear, suffering, and even death. (1) Worldwide, close to six hundred thousand women every day lose their lives during pregnancy or childbirth. In 2000 , it was estimated that approximately 529000 women died from consequences of pregnancy or delivery. Developed countries account for around one percent only of these deaths, while ninety-nine percent occur in developing countries. ${ }^{(2-4)}$ The causes of maternal deaths include haemorrhage, complication of abortion, and obstetric complications such as

\footnotetext{
*Gynecologic and Midwifery Nursing Department, Faculty of Nursing, Alexandria University
} 
dystosia, eclampsia, sepsis, and of their families. So, their deaths infections. ${ }^{(4-6)}$ A quality antenatal clinics represent a drain on all development (ANCs) and recipient of professional efforts and it is a tragedy with major delivery care have a profound effect on consequences for the whole family. It is reduction of maternal deaths. ${ }^{(7,8)}$

a double tragedy when the death could

Early and regular antenatal checkup have been avoided. Prevention of by trained medical providers are very maternal morbidity and mortality is not important in assessing the physical only a social and economic request, but status of woman and her fetus during pregnancy. ${ }^{(9)}$ also it is a moral imperative, and failure to save mothers' lives is a denial of

Between $25 \%$ to $33 \%$ of all deaths of women of reproductive age in many women's fundamental human right. ${ }^{(12)}$

Antenatal care is a preventive developing countries are the result of complications of pregnancy or childbirth. ${ }^{10,11)}$ The health of mothers and children is recognized to be closely related to the general health of the community, as they constitute more than two-thirds of any community. In fact, the women who die from maternal causes are in the prime of their lives and are responsible for the health and well being obstetric health program that aims at optimizing maternal-fetal outcome, through regular monitoring of pregnancy. ${ }^{(9,13,14)} \quad$ In $\quad$ developing countries, only $65 \%$ of women receive antenatal care; $63 \%$ in Africa; 65\% in Asia; and $73 \%$ in Latin America and the Caribbean. In developed countries, 97\% of women receive antenatal care. Furthermore, only $53 \%$ of deliveries in 
developing countries take place with the assistance of skilled birth attendant (WHO 1997). ${ }^{(15)}$ In recent years, the Egyptian government conducted several investigations on maternal mortality. It was found that $39.1 \%$ of pregnant women had antenatal care, and only $28.5 \%$ had the recommended four or more antenatal visits. ${ }^{(16)}$ The World Health Organization (WHO) reported that one of the main reasons that women do not seek maternity care or return to the health centers as advised is the poor quality of care rendered, cost of the services, lack of access to the facility, and long waiting time. Most of them do not attend for follow-up, but to seek help for health problems. ${ }^{(16,17)}$

Among safe motherhood advocates, antenatal care has been downplayed in recent years as an intervention for reducing maternal mortality. This has arisen in large part as a result of improved understanding of the causal pathways that lead to maternal deaths, notably absence of effective management for obstetric complications. Some life-threatening complications can be prevented antenataly, most requiring interventions at the time of delivery and the immediate postpartum period. Most safe motherhood programmes therefore currently stress ensuring that all women benefit from the care of a skilled health care professional during pregnancy, delivery, and postpartum period.

In these circumstances, it is not surprising that little attention has been paid to patterns and trends in antenatal care use. Yet there is ample evidence that care during the antenatal period represents an opportunity to deliver interventions that will improve maternal health, prenatal health, and, more than 
likely, prenatal survival. Moreover, HIV/ patients who are usually referred from AIDS epidemic has directed more local primary health care centers. These attention to the antenatal period as an hospitals were:

entry point for HIV/ AIDS prevention and

1. Alexandria governorate hospital, care initiatives. representing the Ministry of Health

\section{Aim of the study} and Population (MOHP).

The aims of this study was to:-

2. El-Shateby Maternity Hospital,

- Assess pregnant women utilization of antenatal care services in maternity hospitals in Alexandria.

- Find out factors affecting pregnant women's utilization of antennal care services in the selected settings.

\section{MATERIAL AND METHODS}

Study design: cross sectional

Setting:

The study was carried out in four maternity hospitals in Alexandria. The hospitals represent the different agencies involved in the provision of antenatal care to pregnant women in representing the University of Alexandria medical services.

3. Dar Elwelada Hospital, representing Medical Care Organization.

4. Gamal Abd El-Nasser Hospital, representing the Health Insurance Organization (HIO).

\section{Subject:}

50 women from each of the previously mentioned setting affiliated to different organizations that are concerned with provision of antenatal services in Alexandria hospitals.

$\underline{\text { Tool: }}$

Alexandria as well as high risk antenatal 
One tool was developed and used for data collection. A structured interview schedule was developed based on thorough review of current literature and up to date data and was used to collect the necessary data about the study sample. It was divided into two parts:

- The first part concerning with biosocial characteristics of the sample such as age, education, occupation, marital status, family income, gravidity, parity, no. of abortions, no. of living children, history of previous diseases, history of associated diseases with pregnancy, and current pregnancy.

- The second part concerning with utilization of antenatal care facility such as time of initial visits, adequacy of visits / pregnancy, reasons for each visit, regular or interrupted visits, and its reasons.
Scoring system :

A scoring system for knowledge of women regarding antenatal care was used. The possible range of scores was from 0 to 2, a score of two was given to correct and complete answer, a score of one was given to correct and incomplete answer. and a score of 0 was given to the wrong answer

\section{Methods}

The steps to be followed in this study were:

Permission to carry out this study was obtained from the responsible authorities of the selected settings. The researcher explained the purpose of the research to the study sample, and obtained the sample approval to share on the research. Data collection was conducted in postpartum wards of the previously mentioned setting, each woman was interviewed for about 30 minutes. 
Interviewing technique was used to (54.50\%) were primigravida, (59\%) assess the women utilization adequacy were nullipara, and (26.5\%) had 1-2 whether adequate, intermediate or abortion. As regards complications only inadequate according to Kessner (table (7.5\%, 3.5\%, and 1.5\%) had 8). (18) The study was implemented for six months ( February- August 2006).

\section{RESULTS}

Table (1) shows the biosocial characteristics of the study sample. The mean age was 29.82 years. Nearly twofifths of the sample (39\%) just read and write, while nearly one quarter of the sample got less than secondary, and one-third had secondary or more education. As regards work experience, one-third of the study sample were housewives (33.5\%), and about one half of them work for cash (49.0\%), only less than one-fifth work without income.

Table (2) represents distribution of the study according to their obstetrical history. It shows that more than one half complications during their pregnancy, labour, and postpartum period, respectively. On the other hand, (13\%) had current pregnancy complications.

Table (3) represents the distribution of the study sample according to their medical and surgical history. It shows that the majority of the study sample $(91.50 \%$ and $98.5 \%)$ did not have any medical or surgical problems respectively, while minorities of them (8.5\% and $2.5 \%$ ) had previous medical and surgical complications.

Table (4) shows the utilization of the study sample of antenatal care service. Nearly half of the sample $(46.5 \%)$ started antenatal care from 1 to 3 months, while about two-fifths (40.5\%) 
started it from 4 to 6 months and only more than one-tenth (13\%) started it from 7 to 9 months. As regards the total number of visits, it shows that more than half of the sample (56\%) had less than 3 visits, one third (33\%) had 3-4 visits, less than one-tenth $(7 \%)$ had $5-8$ visits, and only $4 \%$ of the study sample had 9 visits.

Table (5) represents the distribution of the study sample according to their reasons for attendance to antenatal clinic. It shows that about two-fifths $(39.50 \%)$ stated the reason to be for antenatal care, less than one-fifth stated the reason as for medical reasons, in about $16 \%$ the reason was for vaccination, and in more than one-tenth the reason was to confirm pregnancy. Also, less than one-tenth stated the reason as for booking of delivery.

Table (6) illustrates the distribution of the study sample according to their barriers for utilization of antenatal care. Poor quality of care was the most commonly reported reason (49\%), followed by the cost of service (39.5\%), and long waiting time (11.5\%).

Table (7) clarifies the distribution of the study sample according to their knowledge and their source of knowledge about antenatal care. It shows that three-fifths (60\%) of the study subject had correct and incomplete answer, also more than one-third (35\%) had wrong and didn't know the answer, while only (5\%) had correct and complete answer. As regards source of knowledge, the media was the main source of their knowledge (41\%), followed by the relative $(37 \%)$, then doctor and nurse (34\%). Only (4\%) of the study sample mentioned that the experience as a source of their knowledge about antenatal care. 
Figure (1) shows the distribution of the study sample according to adequacy of the antenatal care. It shows that only more than one-tenth $(11 \%)$ of the study sample received adequate antenatal care (level 1), one-third (33\%) received intermediate antenatal care (level 2), while more than half (56\%) received inadequate antenatal care (level 3).

\section{DISCUSSION}

Pregnancy is a time foe physical and psychological care and preparation for the most important and special relation between the mother and her child.(19,20) Therefore, early and regular antenatal check up by trained medical providers is very important in assessing the physical status of women during pregnancy. Egyptian women received antenatal care from a medical provider for $(70 \%)$ of the births during the five years period before the survey, (EDHS 2005) $)^{(9)}$.
Considering the initial antenatal visit. Backe (2001) has claimed that a pregnant women must begin antenatal care as early as possible following the first missed period. This is because women who start antenatal care late, and those who receive no antenatal care, are at increased risk of poor pregnancy outcomes. (21) In the present study, nearly half of the study group started antenatal care during the $1^{\text {st }}$ trimester, however, a substantial proportion waited until $2^{\text {nd }}$ and $3^{\text {rd }}$ trimester (table 4). These findings disagree with that of Fathy (2005) who stated that (81.4\%) have initiated antenatal care during the $1^{\text {st }}$ trimester and also, it disagrees with that of Mohamed (2004) who found that (86.4\%) of women from a total sample of 300 in Tanta have initiated antenatal care during their $1^{\text {st }}$ trimester. ${ }^{(16,22)}$ 
Regular and careful supervision more than five times.(24) The findings of during antenatal period improve the the present study imply that more efforts chance of early recognition and are needed to educate pregnant women treatment of complications during about the importance of regular pregnancy. Moreover, according to WHO antenatal visits, and the positive recommendations, antenatal care for relationship between regular antenatal normal pregnancies should be a care and pregnancy outcome.

minimum of four visits. In the present Nonetheless, about two-fifths of the study, more than half of the study women attended four antenatal care sample have attended antenatal care (table 5). This probably indicates a less than three visits, while nearly one- positive perception of antenatal care as a third of them had 3-4 times and only health promotion service. On the other slightly of one-tenth had 5 visits or more. hand, poor quality of care, cost of the This result is online with Ahmed who service, and long waiting time are the stated that $(47.0 \%)$ of women had most frequently reported barriers for attended less than four visits and receiving such care (table 6). The same (37.6\%) had attended four visits or barriers were mentioned by two other more.(23) On the other hand, this result studies carried out in Tanta and disagreed with that of Mansour (2000) Zagazig. ${ }^{(25,26)}$

who has reported that slightly less than The main source of knowledge about one-third of women from a total sample antenatal care in this study was mass of 200 were attending antenatal care media followed by relative then by doctor 
and nurse. The literatures suggested that information or knowledge which is drawn from non-professionals may be poor or erroneous, so it can hamper useful attitudes, in this case discourage antenatal visits. ${ }^{(27,28)}$

Regarding the adequacy of antenatal care more than half of the study subjects received inadequate antenatal care (figure 1). Despite this unexpected result other studies point out similar findings. ${ }^{(26,29)}$ This may be attributed to low perceived value of antenatal care or lack of knowledge about it (table 7).

\section{CONCLUSION}

It can be concluded from the present study that the utilization of antenatal care was generally inadequate. The reasons for attendance were for antenatal care, for medical reasons, for confirming pregnancy, for vaccination, and for booking of delivery. On the other hand, barriers for utilization were poor quality of care, cost of the service, and long waiting time.

\section{RECOMMENDATIONS}

Based on the results of the current research, the following recommendations are suggested:

1. There is a need for improving community awareness on maternal health and for motivating women to utilize maternal care services.

2. Ensure each site performing antenatal care has protocols in place for where to and when refer patients and the staff are appropriately trained therein.

3. Promotion of the outreach home visiting programs for detecting and/or promoting the pregnant women awareness about maternal services and refer them to antenatal care clinics. 
4. Adoptions of the new $\mathrm{WHO}$ antenatal care model in our maternal care services to eradicate of women's barrier to attending regularly for antenatal care visits, and that revealed early detection of pregnant complication and that promote maternal health care in our society.

5. Applied training programs of skilled attendants for nurses to improve their quality of care as a health care provider at antenatal clinic.

Table (1): Distribution of the study sample according to their biosocial characteristics.

\begin{tabular}{|c|c|c|}
\hline Biosocial characteristics & $\begin{array}{c}\text { No. } \\
\mathrm{n}=\mathbf{2 0 0}\end{array}$ & $\%$ \\
\hline \multicolumn{3}{|l|}{ Age in years } \\
\hline $\begin{array}{l}<20- \\
25- \\
30- \\
35- \\
40+\end{array}$ & $\begin{array}{c}25 \\
89 \\
61 \\
18 \\
7\end{array}$ & $\begin{array}{c}12.50 \\
44.50 \\
30.50 \\
9.00 \\
3.5\end{array}$ \\
\hline Mean age (years) & \multicolumn{2}{|c|}{29.82} \\
\hline Educational background & & \\
\hline $\begin{array}{l}\text { Read \& write } \\
<\text { Secondary } \\
\text { Secondary + }\end{array}$ & $\begin{array}{l}78 \\
53 \\
69\end{array}$ & $\begin{array}{l}39.00 \\
26.50 \\
34.50\end{array}$ \\
\hline \multicolumn{3}{|l|}{ Work experiences } \\
\hline $\begin{array}{l}\text { Housewife } \\
\text { Work for cash } \\
\text { Work without income }\end{array}$ & $\begin{array}{l}67 \\
98 \\
35 \\
\end{array}$ & $\begin{array}{l}33.50 \\
49.00 \\
17.50\end{array}$ \\
\hline \multicolumn{3}{|l|}{ Marital status } \\
\hline $\begin{array}{l}\text { Married } \\
\text { Other ( divorced- widowed) }\end{array}$ & $\begin{array}{c}183 \\
17\end{array}$ & $\begin{array}{c}91.50 \\
8.50\end{array}$ \\
\hline \multicolumn{3}{|l|}{ Family income } \\
\hline $\begin{array}{l}\text { Less than adequate } \\
\text { Adequate } \\
\text { Adequate and save }\end{array}$ & $\begin{array}{l}89 \\
99 \\
12\end{array}$ & $\begin{array}{l}44.50 \\
49.50 \\
6.00\end{array}$ \\
\hline
\end{tabular}


Table (2) Distribution of the study sample according to their obstetric history.

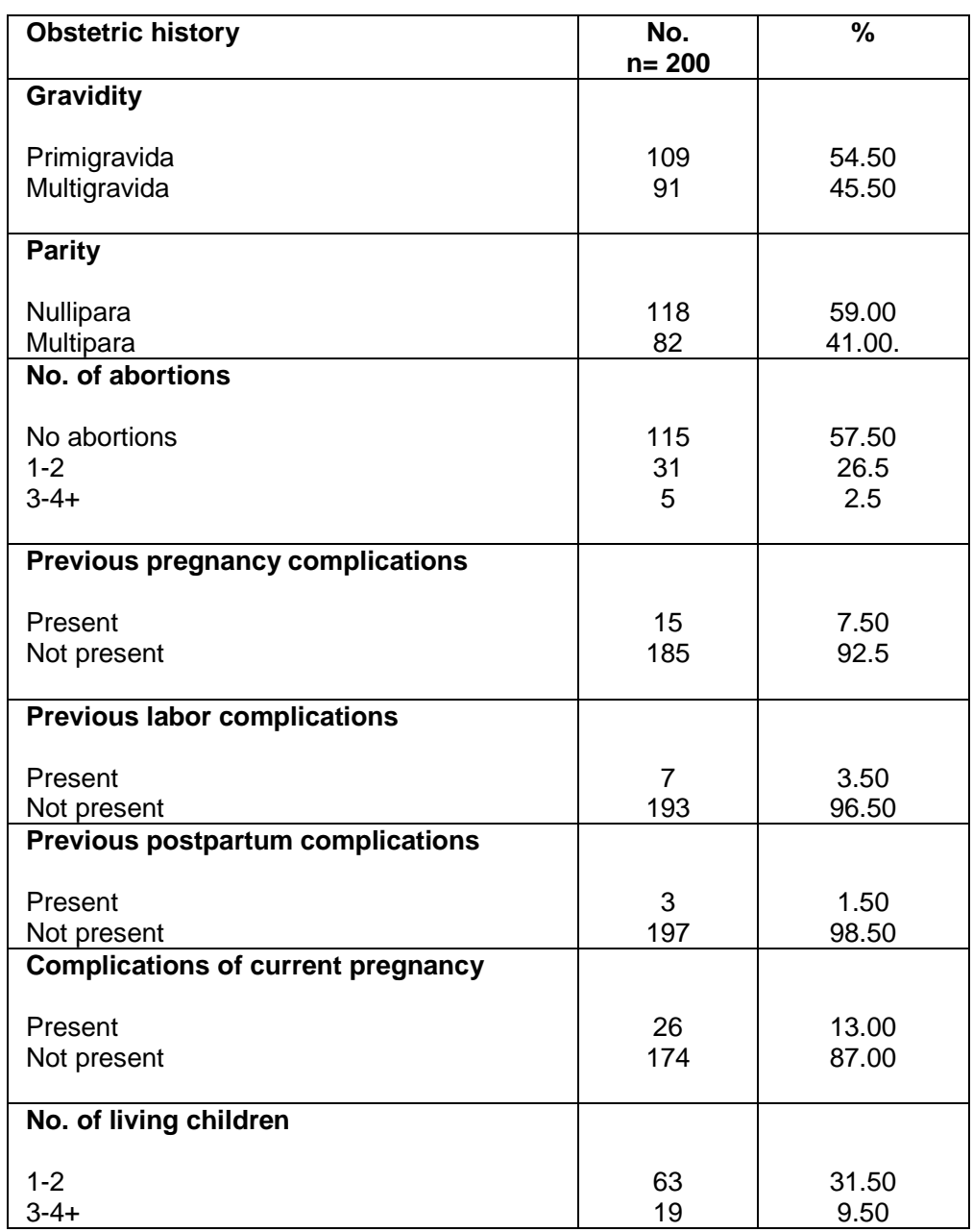


Table (3) Distribution of the study sample according to their medical and surgical history.

\begin{tabular}{|l|c|c|}
\hline Medical and surgical history & $\begin{array}{c}\text { No. } \\
\mathbf{n = 2 0 0}\end{array}$ & $\%$ \\
\hline History of previous medical condition & & \\
Present & 17 & 8.50 \\
Not present & 183 & 91.50 \\
\hline History of previous surgical condition & & \\
Present & 5 & 2.50 \\
Not present & 195 & 98.50 \\
\end{tabular}

Table (4) Distribution of the study sample according to their utilization of antenatal care facility

\begin{tabular}{|l|c|c|}
\hline Utilization of antenatal care & $\begin{array}{c}\text { No. } \\
\mathbf{n = 2 0 0}\end{array}$ & $\%$ \\
\hline Initial visit started & & \\
& 93 & 46.50 \\
1-3 months & 81 & 40.50 \\
4-6 months & 26 & 13.00 \\
7-9 months & & \\
& & \\
\hline Total number of visits & 112 & 56.00 \\
>3 & 66 & 33.00 \\
3- & 14 & 7.00 \\
5- & 8 & 4.00 \\
\hline+ & & \\
\hline
\end{tabular}

Table (5) Distribution of the study sample according to their reasons for attendance.

\begin{tabular}{|l|c|c|}
\hline Reasons for attendance of antenatal & $\begin{array}{c}\text { No. } \\
\mathbf{n}=\mathbf{2 0 0}\end{array}$ & $\%$ \\
\hline care & 28 & 14.00 \\
Me confirm pregnancy & 37 & 18.50 \\
For antenatal care & 79 & 39.50 \\
Vaccination & 32 & 16.00 \\
Booking of delivery & 24 & 12.00 \\
& & \\
\hline
\end{tabular}


Table (6) Distribution of the study sample according to their barriers for not attending antenatal care

\begin{tabular}{|l|c|c|}
\hline Barriers for antenatal care & $\begin{array}{c}\text { No. } \\
\mathbf{n = 2 0 0}\end{array}$ & $\%$ \\
\hline Cost of the services & 79 & 39.50 \\
Poor quality care & 98 & 49.00 \\
Long waiting time & 23 & 11.50 \\
& & \\
\hline
\end{tabular}

Table (7) Distribution of the study sample according to their knowledge source of knowledge about antenatal care .

\begin{tabular}{|l|c|c|}
\hline Knowledge and source of knowledge about ANC & $\begin{array}{c}\text { No. } \\
\mathbf{n = 2 0 0}\end{array}$ & $\%$ \\
\hline Knowledge about ANC & 10 & 5.00 \\
1- Correct and complete & 120 & 60.00 \\
2- Correct and incomplete & 70 & 35.00 \\
3- Wrong and don't know & & \\
\hline - Source of knowledge & 75 & 37.50 \\
1- Relative & 20 & 10.00 \\
2- Previous experience & 68 & 34.00 \\
3- Doctor and nurse & 82 & 41.00 \\
4- Media & & \\
\hline
\end{tabular}

* There is more than one answer

Table (8) Pattern of attendance to antenatal care according to Kessner index.

\begin{tabular}{|c|c|c|c|}
\hline $\begin{array}{l}\text { Antenatal } \\
\text { index }\end{array}$ & $\begin{array}{c}\text { Months in which prenatal care } \\
\text { began }\end{array}$ & $\begin{array}{l}\text { Gestation } \\
\text { (weeks) }\end{array}$ & $\begin{array}{l}\text { Number of antenatal } \\
\text { visits }\end{array}$ \\
\hline $\begin{array}{l}\text { Level } 1 \\
\text { adequate }\end{array}$ & Within first 3 months & $\begin{array}{c}\text { and } 13 \text { or less } \\
14-17 \\
18-21 \\
22-25 \\
26-29 \\
30-31 \\
32-33 \\
34-35 \\
36 \text { or more }\end{array}$ & $\begin{array}{l}\text { and } 1 \text { or more or not } \\
\text { stated } \\
\text { and } 2 \text { or more } \\
\text { and } 3 \text { or more } \\
\text { and } 4 \text { or more } \\
\text { and } 5 \text { or more } \\
\text { and } 6 \text { or more } \\
\text { and } 7 \text { or more } \\
\text { and } 8 \text { or more } \\
\text { and } 9 \text { or more }\end{array}$ \\
\hline $\begin{array}{l}\text { Level } 2 \\
\text { intermediate }\end{array}$ & \multicolumn{3}{|c|}{ All combinations other than specified for level 1 and 3} \\
\hline $\begin{array}{l}\text { Level } 3 \\
\text { inadequate }\end{array}$ & Seventh month or later, No care & 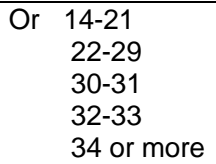 & $\begin{array}{l}\text { and } 0 \text { or not stated } \\
\text { and } 1 \text { or less or not stated } \\
\text { and } 2 \text { or less or not stated } \\
\text { and } 3 \text { or less or not stated } \\
\text { and } 4 \text { or less or not stated }\end{array}$ \\
\hline
\end{tabular}




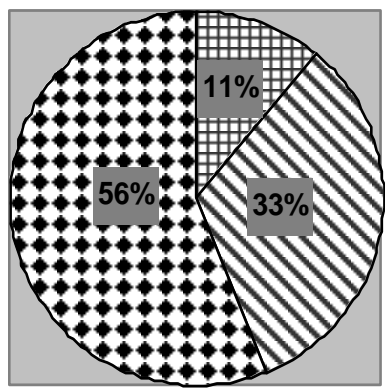

\begin{tabular}{|l|}
\hline Adequate \\
antenatal care \\
(level 1) \\
Intermediate \\
antenatal care \\
(level 2) \\
Inadequate \\
antenatal care \\
(level 3)
\end{tabular}

Figure (1) Distribution of women according to adequacy of antenatal care

\section{REFERENCES}

1- World Health Organization, UNICEF, UNFPA. Maternal mortality in 2000: estimates and UNFPA. Geneva, Switzerland: WHO; 2004.

2- World Health Organization. Mother baby package: implementing safe motherhood in countries. Geneva: World Health Organization; 1994

3- Inter- Agency Group for Safe Motherhood action agenda: Priority on the safe motherhood technical consultation 18- 23 October 1997. Colombo, Sri Lanka.

4- World Health Organization. Revised 1990 estimates of maternal mortality: a new approach by WHO and UNICEF. Geneva: World Health Organization; 1996.

5- Anonymous. Development and research training in human reproductive. Antenatal services and delivery care 1997; NO. 42, part 1. Available from URL: http// www.pubmedecentral.nih.gov. last accessed on: February 2007.
6- Khan M, Pillay T, Moodley JM, Connolly CA. Maternal mortality associated with tube Durban, South Africa. AIDS.2001; 15: 1857- 63.

7- Magadi M, Madise N, Diamound I. Factors associated with unfavorable birth outcomes: Middle East Journal of Family Medicine.2001; 33: 199225.

8- UNICEF Eastern and Southern Africa Regional Office. Maternal Mortality Reducation.2003.

9- El-Zanaty F, Way AA. Egypt Interm Demographic and Health Survey.2005.

10- The World Bank. Preventing the tragedy of maternal deaths: a report on the international Safe Motherhood Conference. Washington: The World Bank; 1987

11- World Health Organization. Safe Motherhood Progress Report. Geneva: World Health Organization; 1996.

12- World Health Organization. Roystone and Armstronge: 
Preventing maternal deaths. Geneva: World Health Organization; 1989.

13- El-Zanaty F, Way AA. Egypt demographic and health survey. Cairo: National Population Council; 2000. 13.

14- El-Zanaty F, Way AA. Egypt demographic and health survey 2003. Cairo: Ministry of Health and National Population Council.

15- World Health Organization. Antenatal care in developing countries: promises, achievements and missed opportunities: an analysis of trends, Levels and differentials. Geneva: WHO; 19902001:2-23

16- Fathy A. Factors affecting mothers' utilization of antenatal care. Master thesis submitted to Faculty of Nursing, University of Ain Shams. 2005.

17- World Health Organization. Achieving reproductive health for all: the role of WHO. Geneva: World Health Organization; 1995. 6

18- 18- Kessner DM, Suiger Y, Kalik LE. Infant death: an analysis by maternal risk and health care. Washington DC: Institute of Medicine, National Academy of Science; Vol 1, 1973.

19- Coverage of maternal care: a listing of available information (in press): Geneva: WHO; 1997.

20- WHO. The second Decade: improving women health and development. WHO. 1998. 18:6.

21- Backe W. Obstetric and Gynecology. The National Medical series for independent study. W.B. Saunders Co; 2001. 21-27.

22- Mohamed S. Patterns of utilization of antenatal care in Tanta. Doctorate thesis submitted to Faculty of Nursing, Tanta University.2004.

23- Ahmed H. Evaluation of Antenatal care services and women's perception in Assuit University Hospital. AssUniv. Bull. Environ. Res. Vol 9 No. 1, March 2006.

24- Mansour A. Assessment of Antenatal care in an urban area. The New Egyptian Journal of Medicine. 2000; 23(6): 281-7.

25- Nour SA, Ragheb SS, Eshra DK, Abd El-Ghani AS. Pattern of women's attendance to the antenatal care in Zagazig and the factors influencing it. Bulletin of the High Institute of Public Health. 1989; 19;3: 591-608.

26- Mourad M, Gawad BE, Ashmawy $\mathrm{AH}$. Utilization of antenatal care services in Tanta. Bulletin of the High institute of Public Health. 1985; XV (4): 93-106.

27- El-Mahally A, Amer NH, Nazif KM, Eid EM, Abdel Kader HZ. Utilization of maternal health services offered by the Health Insurance Organization in Alexandria. The Journal of the Egyptian Public Health Association. 1997; 72; (3\&4): 34568.

28- Smith CM, Maurer FA. community Health nursing. W.B Saunders Co; 1995. 592.

29- Barrani MAA. Utilization of antenatal health services in Kafr El-Dawar City. Thesis submitted to High Institute of Public Health. University of Alexandria 1998. 